Parenting Style as a Moderator of Associations Between Maternal Disciplinary Strategies and Child Well-Being

By: Anne C. Fletcher, Jill K. Walls, Emily C. Cook, Karis J. Madison, and Tracey H. Bridges

Fletcher, A. C., Walls, J. K., Cook, E. C., Madison, \& K. J., Bridges, T. H. (2008). Parenting Style as a Moderator of Associations between Maternal Disciplinary Strategies and Child Well-Being. Journal of Family Issues, 29, 1724-1744.

Made available courtesy of Sage Publications: http://www.sagepub.com/

*** Reprinted with permission. No further reproduction is authorized without written permission from Sage Publications. This version of the document is not the version of record. Figures and/or pictures may be missing from this format of the document. $* * *$

\begin{abstract}
:
The authors investigate whether parental use of punitive discipline and yielding to coercion varies in levels and associated child outcomes for mothers with different parenting styles. Participants were fourth-grade children $(N=370)$ and their mothers. Maternal parenting style was determined based on levels of responsiveness and demandingness. Authoritative mothers used less punitive discipline than indifferent mothers. Authoritative and authoritarian mothers engaged in less yielding to coercion than indifferent or indulgent mothers. More punitive discipline and yielding to coercion were associated with lower academic grades and more punitive discipline was associated with more social problems, with these effects not moderated by parenting style. Negative effects of yielding to coercion in terms of internalizing, externalizing, and social problems were observed only within authoritarian families. Greater use of punitive discipline was associated with more externalizing problems within the indulgent and authoritarian parenting style groups and more internalizing problems within the authoritarian group.
\end{abstract}

Keywords: parenting style; discipline; practices

Article:

Among child socialization researchers, it is widely recognized that parents play a critical role in relation to children's psychological and behavioral well-being. The empirical literature on parental influences on child adjustment is extensive yet characterized by considerable diversity with respect to the types of parental behaviors and attitudes that have been studied as correlates and predictors of child well-being. Of critical importance within this field have been publications focused on (a) defining and organizing dimensional components of parenting (Baumrind, 1967, 1971; Maccoby \& Martin, 1983) to capture the nature of parental influences in a holistic fashion; and (b) distinguishing between parenting styles and parenting practices (Darling \& Steinberg, 1993). Taken together, these works suggest that the manner in which parenting comes to be linked with children's developmental competence is complex, involving the interplay between the emotional climates parents provide children (parenting styles) and the specific behaviors in which parents engage with the intent of attaining child socialization goals (parenting practices).

Despite the complexity with which parenting styles and parenting practices have been suggested to operate, few investigators have attempted to specify the nature of interactions between these two types of parenting influences. Yet the nature of such interactions is likely to be of critical importance. Is the effectiveness of specific parenting practices, most specifically parental disciplinary strategies, impacted by the stylistic contexts in which they are used? The current effort seeks to answer this question, along with questions relating to the extent to which different parental disciplinary strategies are used by parents with different stylistic profiles. 


\section{Review of the Literature}

\section{History of Parenting Style Research}

The precursors of parenting style research lie in the efforts of various researchers who, individually and working from different methodological and theoretical perspectives, all came to define parenting in terms of the extent to which individuals varied according to two separate attitudinal and behavioral dimensions. This similarity was noted by Darling and Steinberg (1993):

For Symonds (1939), these dimensions included acceptance/rejection and dominance/submission; for Baldwin (1955), emotional warmth/hostility and detachment/involvement; for Schaefer (1959), love/hostility and autonomy/ control; for Sears et al., (1957), warmth and indulgentness/strictness; and for Becker (1964), warmth/hostility and restrictiveness/indulgentness. In retrospect, the similarity of the underlying dimensions proposed by these different researchers is remarkable. (p. 489)

Dimensions such as these are linked to child well-being not just in isolation, but also in terms of the manner in which they interact to describe distinct patterns of parenting. Baumrind $(1967,1971)$ recognized this fact in her work with young children in which she characterized parents as falling into three groups: (1) authoritative (high in warmth and behavioral control); (2) authoritarian (high in behavioral control but low in warmth); and (3) indulgent (low in behavioral control). This work was followed by several attempts to further refine these groups. Baumrind (1991) differentiated parenting styles based on parents of adolescents' levels of assertive control, supportive control, and directive/conventional control, resulting in six parenting style groups. A more widely accepted refinement was proposed by Maccoby and Martin (1983), who described parents in terms of their placement on two dimensions they termed responsiveness and demandingness. According to this classification system, Baumrind's indulgent parents were subdivided into two groups: Indulgent parenting were high in responsiveness and low in demandingness, whereas rejecting (sometimes termed indifferent) parents were low in both responsiveness and demandingness. Following the introduction of this classification was a small avalanche of empirical investigations (see Steinberg, Mounts, Lamborn, \& Dornbusch, 1991) documenting differences between children and adolescents raised in authoritative versus nonauthoritative homes.

\section{Parenting Styles Versus Parenting Practices}

When discussing parenting, it is of critical importance to distinguish between (a) dimensional versus categorical descriptions of parenting style, and (b) parenting styles versus parenting practices. With regards to the first distinction, parenting can be described in terms of either the dimensional components of parenting (namely, parental responsiveness and demandingness) or the different parenting style groups that these dimensions yield (authoritative, indulgent, authoritarian, rejecting). Both conceptualizations of parenting have their own unique advantages. Although a focus on the dimensional components of parenting allows researchers to take advantage of the full range of responses represented through continuous measurement, a stylistic approach permits understanding of the manner in which distinct combinations of these dimensions have different implications for child well-being.

The distinction between parenting styles versus parenting practices is one articulated by Darling and Steinberg (1993) who offered the following definitions of each. Parenting styles were described in terms of the emotional climate provided by parents. For example, an authoritative individual would parent children against a backdrop of warmth and structure. In contrast, parenting practices refer to behaviors in which parents engage with the purpose of attaining specific socialization goals. Examples of parenting practices are parental involvement in schooling, parental monitoring of a child's activities and associates, and parental disciplinary strategies. The relation between styles and practices is complex, in part because parenting practices are one way in which parents express their parenting styles. In this manner, authoritative parents have been demonstrated to be more likely than nonauthoritative parents to engage in certain parenting practices (e.g., be involved in their child's educational experiences; Steinberg, Lamborn, Dornbusch, \& Darling, 1992). Darling and Steinberg also theorized that parenting style would moderate associations between parenting practice variables and indicators of child well-being. Such moderating effects have rarely been investigated. 


\section{Parental Disciplinary Strategies}

Among parenting practices, perhaps none are so widely recognized or controversial as parental disciplinary strategies. For the purposes of the current investigation, we focus on two disciplinary strategies that have been identified as potentially problematic when used by parents. These are (a) power-assertive discipline (Hoffman, 1985), defined in terms of physical punishment, taking away privileges, and issuance of direct commands, (b) and parental inconsistency (Buchanan, Maccoby, \& Dornbusch, 1996; Deal, Halverson, \& Wampler, 1989; Vaughn, Block, \& Block, 1988).

Use of punitive or power-assertive discipline is generally associated with less optimal development among children, although such associations are by no means straightforward. Corporal punishment is associated with short-term compliance (Newsom, Favell, \& Rincover, 1983) but is also linked to subsequent increases in levels of aggressive behavior on the part of children (Strassberg, Dodge, Pettit, \& Bates, 1994). Prevalence of corporal punishment decreases with child age (Wauchope \& Straus, 1990) but presumably use of non-corporal punitive discipline does not. Parental use of punishment, especially in conjunction with the use of reasoning strategies, has been linked with decreases in disruptive behavior among toddlers (Larzelere, Sather, Schneider, Larson, \& Pike, 1998) but is unrelated to prosocial behavior outcomes (see Eisenberg \& Fabes, 1998) and may promote moral reasoning based on fear of punishment (Hoffman, 1985).

The extent to which parents demonstrate consistency in their provision of discipline is related to the development of prosocial behavior and higher levels of moral development among children. When parents do not follow through on their disciplinary strategies, they provide reinforcement for noncompliant behavior and increase the likelihood that the behavior they are attempting to extinguish will reoccur (Patterson, 1997). Inconsistencies in parenting have been linked with higher levels of antisocial behavior among children (Dishion \& Kavanagh, 2003).

Although it has not been studied systematically, there is reason to believe that the disciplinary strategies used by parents may vary systematically according to parenting style. It is possible that parents whose parenting styles are characterized by high levels of both responsiveness and demandingness (authoritative parents) are less likely to use both punitive discipline and inconsistent discipline, due in large part to their provision of a positive parenting context that makes children more responsive to parental disciplinary efforts and results in parents less frequently resorting to problematic disciplinary techniques. Authoritarian parents, whose parenting styles reflect low levels of responsiveness but an emphasis on compliance and behavioral control, may be more likely to use punitive disciplinary techniques. Indulgent parents, who are highly engaged in the parenting process but have difficulties setting behavioral limits, may be particularly likely to engage in inconsistent disciplinary efforts or yield to coercive pressures exerted by children.

\section{Parenting Style as a Potential Moderator of Associations Between Parenting Practices and Indicators of Child Well-Being}

Questions related to whether the consequences of using specific disciplinary strategies might vary depending on the emotional climate in which they are used are of critical importance to researchers and practitioners alike. In other words, might associations between parental disciplinary strategies and indicators of child well-being be moderated by parenting style? It has been suggested that punitive discipline may be less harmful in the context of a warm and supportive parent-child relationship, yet this possibility has not been studied systematically with respect to parenting style. Deater-Deckard, Ivy, and Petrill (2006) reported that positive associations between experiences of use of harsh discipline at age 5 and externalizing behavior during the elementary years were less when parents were high in warmth and positive affect. McLoyd and Smith (2002) found that parental use of physical discipline predicted increases in child problem behavior over time only when it occurred in the context of low levels of emotional support. Schneider, Cavell, and Hughes (2003) found that the use of ineffective discipline was more strongly associated with levels of externalizing behaviors among children when parents were low in perceived containment, a variable that represented parents' establishment of firm limits and ability to stand their ground in conflicts. Taken together, these findings suggest that variables akin to parental 
responsiveness and demandingness moderate associations between parental use of negative disciplinary techniques and child involvement in problem behavior. Yet these findings do not address questions related to whether parenting style may moderate associations between disciplinary practices and child outcomes including, but not limited to, externalizing behavior.

A fundamental principle in parenting style research is that the meaning of any one dimension of parenting style (responsiveness or demandingness) is dependent on levels of the other dimension. Accordingly, authoritative parents and indulgent parents are distinguished by their levels of demandingness, although both groups may score similarly on measures of responsiveness. The role of parenting style as a potential moderator of associations between parental disciplinary practices and child adjustment has not been considered. However, parenting style has been demonstrated to moderate associations between parenting practices, such as parental management of adolescent friendships (Mounts, 2002) and school involvement (Steinberg et al., 1992), and indicators of adolescent well-being.

\section{Research Questions}

We focused on answering two questions within the current investigation. First, we asked whether parents from different parenting style groups differed in their use of punitive discipline and yielding to coercion (akin to parental inconsistency). The highest levels of punitive discipline were hypothesized to be observed among authoritarian parents who are characterized by high levels of demandingness but low levels of responsiveness. Parental use of inconsistent discipline was hypothesized to be greater among parents who were low in demandingness (indulgent and indifferent). Second, we asked whether associations between use of these two disciplinary strategies and indicators of child well-being were moderated by parenting style. We hypothesized that the negative effects of punitive discipline and inconsistent discipline would be greatest within authoritarian parenting families, characterized by high levels of parental demandingness but low levels of responsiveness.

\section{Method}

\section{Participants}

Participants in this study were 370 fourth-grade children and their mothers. Thirty-seven percent of participating dyads self-identified as African American $(n=136)$ and 63\% as European American $(n=234)$. Forty-eight percent of participating children were boys $(n=177)$ and $52 \%$ were girls $(n=193)$. Social class of participating dyads was determined using the Hollingshead Four Factor Index of Social Status (Hollingshead, 1975). Hollingshead scores for the sample ranged from 16 (semiskilled laborers) to 66 (major business persons and professionals), with a mean of 43.2 (medium business personnel and minor professionals) and a standard deviation of 11.61.

\section{Measures}

Demographic information. Mothers provided demographic information during a family roster interview designed specifically for the project. Mothers identified all members of the household along with their age, race, gender, and relationship to the target child. Mothers reported their own highest levels of education and occupational status and provided this information for target children's fathers (if fathers were involved in children's lives). Parental educational and occupational information were used to calculate social class using the Hollingshead Four Factor Index of Social Status (Hollingshead, 1975).

Parenting styles. Dimensions of parenting styles were assessed using the 108-item Children's Report of Parenting Behaviors Inventory (CRPBI; Schludermann \& Schludermann, 1970). The CRPBI was originally developed by Schaefer (1965) as a measure of children's perceptions of their parents' attitudes and behaviors. Several versions of this measure are currently in use. The 108-item version used in this study was developed with special attention to elimination of culturally inappropriate items. The CRPBI consists of 18 subscales and 3 superordinate scales. Children indicate their mothers' perceived similarity to each described behavior on a three-point scale with 1 (my mother is not like), 2 (my mother is a little like), and 3 (my mother is a lot like). Our measure of parental responsiveness was the 8-item Acceptance subscale (alpha =.79). Sample items for this subscale are "makes me feel better after talking over my worries with her" and "enjoys doing things with me." 
Developing a measure of parental demandingness was more challenging given that although several CRPBI subscales contain items that assess the core components of demandingness, other items on these same subscales do not. In addition, the inter-item reliability coefficients for individual subscales were low. We dealt with this difficulty by conducting an exploratory factor analysis with an oblique rotation of all items from the five subscales that comprised the Firm Control Scale (Control, Enforcement, NonEnforcement—reverse coded, Lax Discipline - reverse coded, and Extreme Autonomy - reverse coded). Seven factors emerged, with the first factor accounting for $15 \%$ of the variance and containing items from all five sub-scales that were clearly consistent with our conceptualization of parental demandingness. We combined the 13 items that loaded on this factor to form our measure of parental demandingness. The alpha for this scale was .73, and items were consistent with our conceptualization of parental demandingness including "does not pay much attention to my misbehavior" (reverse coded) and "lets me do anything I like to do" (reverse coded). Items on each scale were averaged to yield measures of responsiveness and demandingness, with higher scores indicative of higher levels of both constructs.

Based on the previously described work of Baumrind (1967, 1971), Maccoby and Martin (1983), and Steinberg, Lamborn, Darling, Mounts, and Dornbusch (1994), we used median splits to designate each family within our sample as high or low in responsiveness and high or low in demandingness. We then assigned each family to one of four parenting style groups. Authoritative families $(n=106)$ were high in both responsiveness and demandingness. Indulgent families $(n=90)$ were high in responsiveness but low in demandingness.

Authoritarian families $(n=73)$ were high in demandingness but low in responsiveness. Indifferent families $(n=$ 101) were low in both responsiveness and demandingness.

Parental disciplinary practices. Children's perceptions of mothers' discipline strategies were assessed using two subscales from the Childrearing Issues Questionnaire (Hetherington, Henderson, \& Reiss, 1999). The Punitive Discipline subscale $(17$ items, alpha $=.85)$ includes questions aimed at identifying mothers' use of negative sanctions such as yelling, spanking, and withholding privileges. Children were asked questions such as "How often has your mother yelled at you for something you did wrong?"; "How often has your mother spanked, slapped, or hit you?"; and "How often has your mother taken away privileges for something you did wrong?" The Yielding to Coercion subscale $(7$ items, alpha $=.73)$ assesses the extent to which parents demonstrate inconsistency within the context of child discipline. Children responded to questions such as "How often has your mother been talked into things easily by you?" and "How often has your mother ignored it when you broke a previously set rule?" Response options for both subscales range from 1 (not at all in the past month) to 7 (more than once a day). Summary scores for parenting practice variables were computed by averaging items within each subscale. Higher scores were indicative of greater use of punitive discipline and yielding to coercion.

Table 1

Descriptive Statistics for Stylistic Dimensions of Parenting, Parenting Practices, and Child Outcomes

\begin{tabular}{lllcl}
\hline Variable & $M$ & $S D$ & Range & $N$ \\
\hline Responsiveness & 2.74 & 0.30 & 1.5 to 3 & 370 \\
Demandingness & 2.61 & 0.24 & 2.08 to 3 & 370 \\
Punitive discipline & 2.11 & 0.82 & 1 to 5.76 & 370 \\
Yielding to coercion & 2.21 & 0.93 & 1 to 5.17 & 370 \\
Grade point average & 3.10 & 0.83 & 0 to 4 & 362 \\
Internalizing behavior & 5.08 & 4.30 & 0 to 28 & 370 \\
Externalizing behavior & 5.27 & 4.94 & 0 to 27 & 370 \\
Social problems & 2.06 & 2.28 & 0 to 13 & 370 \\
\hline
\end{tabular}

Child well-being. Mothers completed the 118-item Child Behavior Checklist (CBCL; Achenbach \& Edelbrock, 1981), designed to measure children's emotional and behavioral problems. For the current effort, 2 groupings and 1 syndrome subscale were used to assess externalizing behaviors, internalizing behaviors, and social problems, respectively.

With the written consent of parents, official fourth-quarter academic grades were obtained from participating schools. Math and language arts grades were reported by teachers and scored on a conventional 4-point scale (A 
$=4.0, \mathrm{~B}=3.0, \mathrm{C}=2.0, \mathrm{D}=1.0, \mathrm{~F}=0.0)$. Grades in these two subjects were then averaged, and the resulting grade point average (GPA) ranged from 0 to 4 , with a mean of 3.09 and a standard deviation of .83 . The means and standard deviations of all variables are presented in Table 1.

\section{Procedure}

Mother/child dyads participated in home interviews conducted by two research assistants in participants' homes or at a location of their choosing. Mothers and children completed questionnaires and answered interview questions separately. All questionnaires were read aloud to children in locations where parents could not overhear interviews. Questionnaires were read aloud to mothers if they appeared to be having difficulty completing measures or if they requested assistance.

Table 2

Intercorrelations Among Stylistic Dimensions of Parenting, Parenting Practices and Child Outcomes

\begin{tabular}{|c|c|c|c|c|c|c|c|}
\hline & 2 & 3 & 4 & 5 & 6 & 7 & 8 \\
\hline 1. Responsiveness & $\begin{array}{r}.24 * * \\
(370)\end{array}$ & $\begin{array}{r}-.21^{* *} \\
(370)\end{array}$ & $\begin{array}{r}-.20 * * \\
(370)\end{array}$ & $\begin{array}{l}.16^{* *} \\
(362)\end{array}$ & $\begin{array}{r}-.04 \\
(370)\end{array}$ & $\begin{array}{l}-.13^{*} \\
(370)\end{array}$ & $\begin{array}{r}-.09 \\
(370)\end{array}$ \\
\hline 2. Demandingness & & $\begin{array}{r}-.10 \\
(370)\end{array}$ & $\begin{array}{r}-.36 * * \\
(370)\end{array}$ & $\begin{array}{r}.09 \\
(362)\end{array}$ & $\begin{array}{r}.06 \\
(370)\end{array}$ & $\begin{array}{r}-.05 \\
(370)\end{array}$ & $\begin{array}{r}.06 \\
(370)\end{array}$ \\
\hline 3. Punitive discipline & & & $\begin{array}{l}.63^{* *} \\
(370)\end{array}$ & $\begin{array}{r}-.24 * * \\
(362)\end{array}$ & $\begin{array}{r}.09 \\
(370)\end{array}$ & $\begin{array}{l}.17 * * \\
(370)\end{array}$ & $\begin{array}{l}.14 * * \\
(370)\end{array}$ \\
\hline 4. Yielding to coercion & & & & $\begin{array}{r}-.22 * * \\
(362)\end{array}$ & $\begin{array}{r}.07 \\
(370)\end{array}$ & $\begin{array}{l}.17 * * \\
(370)\end{array}$ & $\begin{array}{r}.12^{*} \\
(370)\end{array}$ \\
\hline $\begin{array}{l}\text { 5. Grade point } \\
\text { average (GPA) }\end{array}$ & & & & & $\begin{array}{r}-.01 \\
(362)\end{array}$ & $\begin{array}{r}-.23 * * \\
(362)\end{array}$ & $\begin{array}{r}-.20 * * \\
(362)\end{array}$ \\
\hline 6. Internalizing behavior & & & & & & $\begin{array}{l}.52 * * \\
(370)\end{array}$ & $\begin{array}{l}.62^{* *} \\
(370)\end{array}$ \\
\hline 7. Externalizing behavior & & & & & & & $\begin{array}{l}.64 * * \\
(370)\end{array}$ \\
\hline 8. Social problems & & & & & & & \\
\hline
\end{tabular}

\section{Results}

Note: GPA data were not available for all participants; sample sizes indicated by parentheses. ${ }^{*} p<.05 .{ }^{* *} p<.01$.

\section{Intercorrelations Among Variables}

Patterns of intercorrelations among variables (Table 2) indicated that parents who were higher in responsiveness also tended to be more demanding. Higher levels of responsiveness but not demandingness tended to be associated with more optimal child adjustment. Parents who used more punitive discipline tended to engage in more yielding to coercion, and higher levels of both of these variables were linked with less optimal child adjustment. Parents who were higher in responsiveness engaged in less punitive discipline and less yielding to coercion. Parents who were higher in demandingness engaged in less yielding to coercion. Indicators of child well-being tended to cluster together. Associations involving internalizing behaviors tended to deviate from these patterns, with internalizing unassociated with parenting style variables, disciplinary practice variables, or GPA.

Table 3

Mean Levels of Parenting Practice and Outcome Variables Within Parenting Style Groups

\begin{tabular}{lcccc}
\hline & \multicolumn{4}{c}{ Parenting Style } \\
\cline { 2 - 4 } Variable & Indifferent & Indulgent & Authoritarian & Authoritative \\
\hline Academic grades & $2.97^{\mathrm{a}}$ & $3.14^{\mathrm{ab}}$ & $2.89^{\mathrm{a}}$ & $3.31^{\mathrm{b}}$ \\
Internalizing & $5.27^{\mathrm{a}}$ & $4.44^{\mathrm{a}}$ & $5.40^{\mathrm{a}}$ & $5.24^{\mathrm{a}}$ \\
Externalizing & $6.32^{\mathrm{a}}$ & $4.40^{\mathrm{b}}$ & $5.67^{\mathrm{ab}}$ & $4.75^{\mathrm{ab}}$ \\
Social problems & $2.26^{\mathrm{ab}}$ & $1.54^{\mathrm{a}}$ & $2.64^{\mathrm{b}}$ & $1.93^{\mathrm{ab}}$ \\
Punitive discipline & $2.28^{\mathrm{a}}$ & $2.04^{\mathrm{ab}}$ & $2.23^{\mathrm{ab}}$ & $1.91^{\mathrm{b}}$ \\
Yielding to coercion & $2.56^{\mathrm{a}}$ & $2.42^{\mathrm{a}}$ & $1.96^{\mathrm{b}}$ & $1.86^{\mathrm{b}}$ \\
\hline
\end{tabular}

Note: Means sharing superscripts are not significantly different at $p<.05$. 
To determine if mean levels in child outcomes differed by parenting style groups, we conducted one-way ANOVAs with follow up Tukey comparisons (Table 3). The highest academic grades were observed in children of authoritative parents, with these levels being significantly higher than for children from authoritarian and indifferent homes. The highest levels of externalizing problems were reported by indifferent parents, with these levels significantly higher than those reported by indulgent parents. The highest levels of social problems were found among children of authoritarian parents, with these levels significantly higher than for those for children of indulgent parents.

\section{Mean Differences in Levels of Parental Disciplinary Strategies Across Parenting Style Groups}

To determine if disciplinary practice variables differed across parenting style groups, we again conducted oneway ANOVAs with follow-up Tukey comparisons (Table 3). The highest levels of punitive discipline were observed among indifferent parents and the lowest among authoritative parents, with these two groups significantly different from one another. Higher levels of yielding to coercion were observed among indifferent and indulgent parents than among authoritarian and authoritative parents.

\section{Associations Between Parental Disciplinary Strategies and Indicators of Child Well-Being Across Parenting Style Groups}

Data were analyzed using hierarchical multiple regression. The first set of regression analyses (Set 1) was conducted to determine whether parenting style moderated associations between disciplinary practices and each indicator of child well-being. In Step 1, we entered demographic controls of child gender, ethnicity, and social class. In Step 2, we entered dummy coded parenting style variables with authoritative as the reference group. In Step 3, we entered the specific parenting practice variable of interest (punitive discipline or yielding to coercion, both centered). In Step 4, we entered a single interaction term for each dummy-coded parenting style variable with the centered disciplinary practice of interest. Given the well-documented difficulties associated with detecting interaction effects in non-experimental research, we followed the recommendations of Whisman and McClelland (2005) and adopted a $p<.10$ significance level for these interaction terms. When any interaction term was statistically significant at $p<.10$ for a specific outcome, we then conducted a second set (Set 2) of regressions, splitting the sample by parenting style group and conducting regression analyses separately within each group, entering demographic controls on Step 1 and the disciplinary practice of interest on Step 2.

Table 4

\begin{tabular}{|c|c|c|c|c|c|c|c|c|}
\hline \multirow{2}{*}{ Outcome } & \multicolumn{2}{|c|}{ GPA } & \multicolumn{2}{|c|}{ Externalizing } & \multicolumn{2}{|c|}{ Social Problems } & \multicolumn{2}{|c|}{ Internalizing } \\
\hline & $\beta$ & $\Delta R^{2}$ & $\beta$ & $\Delta R^{2}$ & $\beta$ & $\Delta R^{2}$ & $\beta$ & $\Delta R^{2}$ \\
\hline \multicolumn{9}{|l|}{ Step 1} \\
\hline Gender & $-.17 * *$ & & $.10^{*}$ & & -.04 & & -.07 & \\
\hline Ethnicity & $.24 * *$ & & .09 & & .06 & & .10 & \\
\hline Social class & $.39 * *$ & $.30^{* *}$ & $-.17 * *$ & $.03^{* *}$ & $-.23 * *$ & $.05^{* *}$ & -.07 & .01 \\
\hline \multicolumn{9}{|l|}{ Step 2} \\
\hline Indifferent & -.04 & & $.12^{*}$ & & -.07 & & -.03 & \\
\hline Indulgent & .00 & & -.06 & & $-.20 * *$ & & -.12 & \\
\hline Authoritarian & .11 & $.02 *$ & .06 & $.02 *$ & -.11 & $.03 *$ & -.03 & .01 \\
\hline \multicolumn{9}{|l|}{ Step 3} \\
\hline Punitive discipline & $-.12 * *$ & $.01 * *$ & $.14 * *$ & $.02 * *$ & $.11 *$ & $.01 *$ & .10 & .01 \\
\hline \multicolumn{9}{|l|}{ Step 4} \\
\hline Indifferent $\times$ PD & .03 & .00 & -.10 & .01 & -.08 & .00 & -.05 & .00 \\
\hline Indulgent $\times$ PD & .02 & .00 & .04 & .00 & .01 & .00 & .01 & .00 \\
\hline Authoritarian $\times$ PD & .02 & .00 & $.11^{\dagger}$ & $.01^{\dagger}$ & .06 & .00 & $.11^{\dagger}$ & $.01^{\dagger}$ \\
\hline \multicolumn{9}{|l|}{ Step 3} \\
\hline Yielding & $-.11 *$ & $.01 *$ & $.17 * *$ & $.02 * *$ & $.02 *$ & $.14 *$ & $.10^{\dagger}$ & $.01^{\dagger}$ \\
\hline \multicolumn{9}{|l|}{ Step 4} \\
\hline Indifferent & .06 & .00 & $-.12^{\dagger}$ & $.01^{\dagger}$ & $-.12^{\dagger}$ & $.01^{\dagger}$ & -.04 & .00 \\
\hline Indulgent & -.04 & .00 & .00 & .00 & .01 & .00 & -.04 & .00 \\
\hline Authoritarian $\times$ Yield & d .04 & .00 & $.11^{\dagger}$ & $.01^{\dagger}$ & $.11^{\dagger}$ & $.01^{\dagger}$ & $.14^{*}$ & $.02 *$ \\
\hline
\end{tabular}

Note: Step 4 interaction terms were added in separate models. GPA = grade point average; $\mathrm{PD}=$ punitive discipline; yield $=$ yielding to coercion .

${ }^{\dagger} p<.10 .{ }^{*} p<.05 .{ }^{* *} p<.01$.

Results of all regression analyses are shown in Tables 4 and 5. Although not a central focus of the current investigation, Set 1 regression analyses indicated that for three of the four child adjustment outcomes (academic grades, externalizing behaviors, and social problems), addition of dummy-coded parenting style variables 
accounted for a significant amount of variance over and above effects of demographic variables $\left(\Delta R^{2}=.02, F=\right.$ 2.65, $p=.05 ; \Delta R^{2}=.02, F=3.00, p=.03 ; \Delta R^{2}=.03, F=3.36, p=.02$, respectively).

Table 5

Prediction of Childhood Outcomes From Demographic and Disciplinary Practice Variables by Parenting Styles

\begin{tabular}{|c|c|c|c|c|c|c|c|c|c|c|c|c|}
\hline \multirow{2}{*}{$\begin{array}{l}\text { Outcome } \\
\text { Parenting Style }\end{array}$} & \multicolumn{4}{|c|}{ Externalizing } & \multicolumn{4}{|c|}{ Internalizing } & \multicolumn{4}{|c|}{ Social Problems } \\
\hline & $\beta$ & $S E$ & $\beta$ & $\Delta R^{2}$ & $\beta$ & $S E$ & $\beta$ & $\Delta R^{2}$ & $\beta$ & $S E$ & $\beta$ & $\Delta R^{2}$ \\
\hline \multicolumn{13}{|l|}{ Indifferent } \\
\hline \multicolumn{13}{|l|}{ Step 1} \\
\hline Gender & 1.45 & 1.09 & .13 & & -1.14 & .85 & -.13 & & -.64 & .48 & -.13 & \\
\hline Ethnicity & 1.50 & 1.29 & .13 & & 2.63 & 1.01 & $.29^{*}$ & & 1.06 & .57 & .21 & \\
\hline Social class & -.09 & .05 & -.23 & .05 & -.06 & .04 & -.20 & $.09 *$ & -.05 & .02 & $-.26 *$ & $.08 *$ \\
\hline Step 2 & & & & & & & & & & & & \\
\hline Punitive discipline & -.04 & .73 & -.01 & .00 & .29 & .57 & .05 & .00 & & & & \\
\hline Step 2 & 09 & 59 & 02 & 0 & & & & 01 & & & 03 & 00 \\
\hline \multirow{2}{*}{\multicolumn{13}{|c|}{$\begin{array}{l}\text { Indulgent } \\
\text { Step 1 }\end{array}$}} \\
\hline Step 1 & & & & & & & & & & & & \\
\hline Gender & .61 & .90 & .07 & & -1.07 & .95 & -.12 & & -.38 & .40 & -.10 & \\
\hline Ethnicity & 1.39 & 1.20 & .14 & & .03 & 1.27 & .00 & & .09 & .53 & .02 & \\
\hline Social class & -.10 & .05 & -.23 & .05 & .01 & .05 & .02 & .02 & -.04 & .02 & $-.24 *$ & .07 \\
\hline \multicolumn{13}{|l|}{ Step 2} \\
\hline Punitive discipline & 1.23 & .56 & $.23^{*}$ & $.05^{*}$ & .58 & .60 & .11 & .01 & & & & \\
\hline Step 2 & & & & & & & & & & & & \\
\hline Yielding & .88 & .51 & .19 & .03 & .21 & .55 & .04 & .00 & .36 & .23 & .17 & .03 \\
\hline \multirow{2}{*}{\multicolumn{13}{|c|}{ Authoritarian }} \\
\hline Step 1 & & & & & & & & & & & & \\
\hline Gender & .99 & 1.25 & .09 & & .28 & 1.17 & .03 & & .07 & .64 & .01 & \\
\hline Ethnicity & 2.46 & 1.34 & .23 & & 1.11 & 1.25 & .11 & & .30 & .68 & .05 & \\
\hline Social class & -.12 & .06 & $-.26 *$ & .09 & -.03 & .05 & -.08 & .01 & -.07 & .03 & $-.27 *$ & .07 \\
\hline \multicolumn{13}{|l|}{ Step 2 } \\
\hline Punitive discipline & 1.73 & .66 & $.30^{*}$ & $.08 *$ & 1.29 & .63 & $.25^{*}$ & $.06 *$ & & & & \\
\hline Step 2 & & & & & & & & & & & & \\
\hline Yielding & 2.03 & .70 & $.32 * *$ & $.10^{* *}$ & 1.71 & .66 & $.30^{*}$ & $.09^{*}$ & .79 & .36 & $.25 *$ & $.06 *$ \\
\hline \multirow{2}{*}{\multicolumn{13}{|c|}{$\begin{array}{l}\text { Authoritative } \\
\text { Step 1 }\end{array}$}} \\
\hline & & & & & & & & & & & & \\
\hline Gender & 1.12 & .87 & .13 & & -.28 & .73 & -.04 & & .22 & .39 & .06 & \\
\hline Ethnicity & -.13 & .92 & -.02 & & .39 & .77 & .05 & & .24 & .41 & .06 & \\
\hline Social class & .01 & .04 & .02 & .01 & -.00 & .04 & -.01 & .00 & -.03 & .02 & -.16 & .03 \\
\hline \multicolumn{13}{|l|}{ Step 2} \\
\hline Punitive discipline & .27 & .59 & .05 & .00 & -.07 & .49 & -.01 & .00 & & & & \\
\hline Step 2 & & & & & & & & & & & & \\
\hline Yielding & .77 & .56 & .02 & .02 & -.02 & .47 & -.00 & .00 & .40 & .25 & .16 & .02 \\
\hline
\end{tabular}

Prediction of academic grades. Set 1 regression analyses indicated that parenting style did not moderate associations between disciplinary practice and academic grades. Accordingly, Set 2 regression analyses were not conducted for this outcome. Over and above the effects of demographic controls and parenting style variables, both punitive discipline and yielding to coercion (entered in different models) were linked with lower academic grades $(t(361)=-2.76, p=.01 ; t(361)=-2.41, p=.02$, respectively) with corresponding and significant changes in $R^{2}$ of $1 \%$ with the addition of each discipline variable.

Prediction of externalizing behaviors. Set 1 regression analyses were statistically significant for both disciplinary practices. For punitive discipline, the Punitive Discipline $\times$ Authoritarian term was significant, $t(369)=-1.84, p=.07$. For yielding to coercion, the Yielding to Coercion $\times$ Indifferent, $t(369)=-1.95, p=.05$, and Yielding to Coercion $\times$ Authoritarian, $t(369)=2.40, p=.05$, terms were significant. Accordingly, regressions examining associations between both disciplinary practices and externalizing behaviors were conducted separately within each parenting style group. Higher levels of punitive discipline were associated with more externalizing behaviors in both the indulgent, $t(89)=2.20, p=.03$, and authoritarian groups, $t(72)=$ $2.61, p=.01$. Higher levels of yielding to coercion were associated with more externalizing behaviors only in the authoritarian group, $t(72)=-2.92, p=.01$.

Prediction of social problems. Set 1 regression analyses indicated significant interaction effects only for yielding to coercion, Yielding to Coercion $\times$ Indifferent, $t(369)=-1.95, p=.05$ and Yielding to Coercion $\times$ 
Authoritarian, $t(369)=1.86, p=.06$. Accordingly, we considered only Set 1 regression analyses for punitive discipline. Higher levels of punitive discipline were associated with more social problems, $t(369)=2.55, p=$ .01. Regressions for yielding to coercion were conducted separately within each parenting style group (Set 2 regression analyses). Within the authoritarian group only, higher levels of yielding to coercion were associated with more social problems, $t(100)=2.17, p=.03$.

Prediction of internalizing behaviors. Set 1 regression analyses indicated significant interaction terms both for yielding to coercion, Yielding to Coercion $\times$ Authoritarian, $t(369)=2.40, p=.02$, and for punitive discipline, Yielding to Coercion $\times$ Authoritarian, $t(369)=1.72, p=.09$. Accordingly, all regressions were conducted separately within each parenting style group. Within the authoritarian group only, higher levels of yielding to coercion were associated with more internalizing behaviors, $t(72)=2.61, p=.01$. Within the authoritarian group only, higher levels of punitive discipline were associated with more internalizing behaviors, $t(72)=2.05$, $p=.04$.

\section{Discussion}

Findings indicated that authoritative mothers used the least punitive discipline and indifferent mothers the most. Authoritative and authoritarian mothers engaged in lower levels of yielding to coercion than did indifferent and indulgent mothers. Associations between parental use of negative disciplinary strategies and indicators of child well-being varied based on child outcome, disciplinary strategy, and parenting style group. Parents who used more punitive discipline and yielding to coercion had children who received lower academic grades, and parents who used more punitive discipline had children with more social problems. These associations did not vary across parenting style groups. Within the indulgent parenting style group, more use of punitive discipline was associated with higher levels of externalizing behavior. Within the authoritarian group, higher levels of punitive discipline were linked with more internalizing and externalizing behavior, whereas higher levels of yielding to coercion were linked with higher levels of internalizing, externalizing, and social problems.

Our findings concerning associations between parenting style and indicators of child well-being are consistent with a large body of literature (see Steinberg et al., 1991) indicating that children demonstrate the most positive development when they experience parenting that is high in both responsiveness and demandingness (authoritative parenting). At the other extreme, children demonstrate the most problematic development when parents score low on both of these dimensions (indifferent parenting). This pattern of findings can be explained by both the influence of parents on children and by child effects, which may shape parenting styles.

Unique to the current study are findings indicating that mothers from different parenting style groups differ in the use of both punitive discipline and yielding to coercion. Punitive discipline was most likely to be used by indifferent parents and least likely to be used by authoritative parents. The positive emotional climate within authoritative homes likely incline parents to explore disciplinary alternatives that are more sensitive to children's needs, such as the use of inductive reasoning. In contrast, indifferent parents are characterized by a lack of closeness in parent-child relationships and had children with the highest levels of externalizing behavior within our sample. The combination of these factors may lead to parents who become frustrated by a child's behavior, using punitive discipline rather than exploring more child-centered disciplinary alternatives.

The highest levels of yielding to coercion were reported for indulgent and indifferent parents, both of whom are characterized by low levels of demandingness. It is likely that parents who have lower expectations for children in terms of mature and appropriate behavior are more easily swayed by circumstances and child arguments regarding disciplinary consequences. Perhaps this tendency to be less consistent and more easily influenced is because of such parents having behavioral expectations that are less considered and thus subject to change across time and circumstance.

In terms of parental use of punitive discipline, our findings indicated that when mothers used more punitive discipline, children had lower levels of academic achievement and more social problems, with this association not being moderated by parenting style. Strassberg et al. (1994) linked parental use of corporal discipline with 
higher levels of externalizing behavior among children. However, our findings differ from this earlier work in that the negative correlates of parental use of punitive discipline were observed for different aspects of child well-being. In part, this may be accounted for by our use of a measure of punitive discipline that incorporated both corporal and non-corporal punishment.

Our most noteworthy findings involved the moderating role of parenting style with respect to associations between disciplinary practices and indicators of child well-being. We found that for several indicators of child well-being, negative associations with punitive discipline and yielding to coercion were evident only within the authoritarian parenting style group. For example, inconsistency in the application of child discipline by authoritarian parents was linked with higher levels of internalizing, externalizing, and social problems. We propose that authoritarian parenting provides a context that places children at particular risk when their parents are inconsistent in the application of discipline. Parental yielding to coercion is inconsistent with the basic tenets of authoritarian parenting, which holds that children should comply with parental demands without discussion. When mothers who are high in demandingness waiver in their behavioral expectations of children, the children may experience this inconsistency as particularly stressful. Although this would also be true for children from authoritative homes, the close parent-child relationships characteristic of authoritative parenting likely insulate children from the negative manifestations of this stress. In addition, the work of Patterson and associates (Patterson, 1997) suggests that some parents are characterized by a tendency to make demands on children (characteristic of authoritarian parents) and then drop these demands when children respond to the demands in a negative fashion. Within such families, parental yielding is indicative of dysfunctional parent-child interactions and is associated with problematic development on the part of the child. Such a process is more likely to characterize authoritarian families than authoritative families, in which parents' decisions to modify rules and consequences are more likely to result from give-and-take discussion regarding parental expectations. Such differences in how yielding to coercion is expressed within the context of different parenting styles may account for the pattern of findings reported here. Authoritarian parents are by definition likely to place behavioral demands on children. If they then change these demands in response to negative responses of children, they may have children who experience more problematic development. The bidirectional nature of parent-child relationships suggests that children who are experiencing more problematic development may also be more likely to push their parents to decrease behavioral demands.

Greater use of punitive discipline was associated with higher levels of internalizing and externalizing behavior only within the authoritarian group. This may be accounted for by differences in the manner in which punitive discipline is used by authoritarian parents, as opposed to parents from other parenting style groups. The combination of high levels of demandingness and low levels of responsiveness on the part of authoritarian parents may make it more likely that they will use harsher and more physical manifestations of punitive discipline (e.g., striking their children), which may be more strongly linked with problematic child development than parenting behaviors such as sending children to their rooms or withholding privileges.

Interestingly, authoritarian parenting did not constitute a context of special risk in terms of the impact of parental inconsistency on academic achievement. Yielding to coercion was linked with lower academic grades, with no moderating effect of parenting style. When parents are inconsistent in their enforcement of household rules and consequences, it is likely to negatively impact children's academic performance, namely that homework is not completed and studying occurs intermittently. Because the implications of failing to complete home-based school assignments are experienced outside the home environment, high levels of parental responsiveness are likely not able to insulate children from their negative repercussions.

The current project represents an initial effort to understand the manner in which parenting styles and parenting practices work together to shape child adjustment. Yet the data on which our conclusions are based are not without limitations. Of greatest concern are the cross-sectional nature of observations, the relative adjustment of our sample, and the demographic profile of our participants. 
Our data were collected at a single point in time. Accordingly, analysis cannot address issues related to the directionality of effects observed. Our focus within this project was on the role of parents as potential influences on children's well-being, yet clearly there are bidirectional influences flowing between children and parents (Bell, 1979). Just as parents influence the likelihood that children will engage in specific behaviors and exhibit particular adjustment profiles, children's behaviors shape the parenting that they receive. In all likelihood, having children who were experiencing adjustment difficulties prompted parents to increase their use of various disciplinary practices in an effort to crack down on problem behaviors. Such an explanation likely explains a portion of associations between maternal use of punitive discipline and indicators of problematic child adjustment. Further research in this area should use longitudinal data in an effort to untangle the direction of effects at work in the associations observed here.

To participate in this study, mothers had to return consent forms to children's schools and provide a working telephone number at which they could be reached. They then had to allow researchers to spend an hour or more in their homes collecting data. It is likely that mothers experiencing parenting difficulties, or whose children were experiencing problems at home and school, were less likely to participate in the current project. This likely restricted our range of parenting behaviors and child adjustment variables and resulted in median splits of responsiveness and demandingness that placed a number of families below medians whose parenting was not severely impaired. However, error within groupings would make it more, not less, difficult to detect parenting effects. Accordingly, our findings are all the more compelling for having been observed within a communitybased sample of relatively well-adjusted parents and children.

Finally, our sample was restricted to fourth-grade children and their mothers from two racial groups and who resided in the southeastern portion of the United States. Accordingly, the findings presented here cannot be generalized to younger children or adolescents, to fathers, or to families from other racial or geographic backgrounds. Although parenting style research has generally found effects to be consistent across a wide variety of individual and family characteristics (Steinberg et al, 1991), it is possible that the manner in which parenting styles and practices work together is, to some extent, shaped by the social circumstances of families' lives. Further research in this area should focus on extending our findings to samples that differ from our own in terms of parent gender, child age, race and ethnicity, and geographical region.

Parenting researchers have long been concerned with documenting the nature of associations between parenting behaviors and attitudes and the psychological and behavioral adjustment of children. The study of parenting has typically been framed by distinct literatures that have focused either on parenting styles or on parenting practices in relation to child well-being. Yet, despite theoretical work (Darling \& Steinberg, 1993) suggesting that these parenting styles and practices work together in complicated and meaningful ways, there have been few empirical efforts designed to specify the nature of such interactions. The findings reported here suggest that parenting styles shape both the disciplinary practices that will be used by parents and the manner in which these practices will be related to child socialization goals. Parenting researchers and practitioners alike should take into account such effects when designing studies or interventions that focus on the role of parents in relation to child well-being.

\section{References}

Achenbach, T. M., \& Edelbrock, C. S. (1981). Behavioral problems and competencies reported by parents of normal and disturbed children aged 4 through 16. Monographs of the Society for Research on Child

Development, 46(10, Serial No. 188).

Baumrind, D. (1967). Child care practices anteceding three patterns of preschool behavior. Genetic Psychology Monographs, 75, 43-88.

Baumrind, D. (1971). Current patterns of parental authority. Developmental Psychology Monograph, 4(1, Pt. 2). Baumrind, D. (1991). The influence of parenting style on adolescent competence and substance use. The Journal of Early Adolescence, 11, 56-95.

Bell, R. Q. (1979). Parent, child, and reciprocal influences. American Psychologist, 34, 821-826. Buchanan, C., Maccoby, E., \& Dornbusch, S. (1996). Adolescents after divorce. Cambridge, MA: Harvard University Press. 
Darling, N., \& Steinberg, L. (1993). Parenting style as context: An integrative model. Psychological Bulletin, 113, 487-496.

Deal, J. E., Halverson, C. F., \& Wampler, K. S. (1989). Parental agreement on childrearing orientations:

Relations to parental, marital, family, and child characteristics. Child Development, 60,1025-1034.

Deater-Deckard, K., Ivy, L., \& Petrill, S. A. (2006). Maternal warmth moderates the link between physical punishment and child externalizing problems: A parent-offspring behavior genetic analysis. Parenting, 6,59-78. Dishion, T. J., \& Kavanagh, K. (2003). Intervening in adolescent problem behavior: A family-centered approach. New York: Guilford Press.

Eisenberg, N., \& Fabes, R. A. (1998). Prosocial development. In W. Damon \& N. Eisenberg (Eds.), Handbook of child psychology: Vol. 3. Social, emotional, and personality development (5th ed., pp. 701-778). New York: John Wiley.

Hetherington, E., Henderson, S. H., \& Reiss, D. (1999). Adolescent siblings in stepfamilies: Family functionality and adolescent adjustment. Monographs of the Society for Research in Child Development, 64, v222.

Hoffman, M. L. (1985). Affective and cognitive processes in moral internalization: An information processing approach. In E. T. Higgins, D. Ruble, \& W. Hartup (Eds.), Social cognition and social development: A sociocultural perspective (pp. 236-274). Cambridge: Cambridge University Press.

Hollingshead, A. (1975). Four factor index of social status. Unpublished manuscript. Yale University. Larzelere, R. E., Sather, P. R., Schneider, W. N., Larson, D. B., \& Pike, P. L. (1998). Punishment enhances reasoning's effectiveness as a disciplinary response to toddlers. Journal of Marriage and the Family, 60, 388403.

Maccoby, E. E., \& Martin, J. A. (1983). Socialization in the context of the family: Parent-child interaction. In P. H. Mussen \& E. M. Hetherington (Eds.), Handbook of child psychology: Vol. 4. Socialization, personality, and social development (4th ed., pp. 1-101). New York: John Wiley.

McLoyd, V. C., \& Smith, J. (2002). Physical discipline and behavior problems in African American, European American, and Hispanic children: Emotional support as a moderator. Journal of Marriage and Family,64,40-53. Mounts, N. S. (2002). Parental management of adolescent peer relationships in context: The role of parenting style. Journal of Family Psychology, 16, 58-69.

Newsome, C., Favell, J. E., \& Rincover, A. (1983). Side effects of punishment. In S. Axelrod \& J. Apsche (Eds.), The effects of punishment on human behavior (pp. 285-316). New York: Academic Press.

Patterson, G. R. (1997). Performance models of parenting: A social interactional perspective. In J. E. Grusec \& L. Kuczynski (Eds.), Parenting and children's internalization of values (pp. 193-226). New York: John Wiley. Schaefer, E. (1965). Children's reports of parental behavior: An inventory. Child Development, 36, 413-424. Schludermann, E., \& Schludermann, S. (1970). Replicability of factors in children's reports of parent behavior (CRPBI). Journal of Psychology, 76, 239-249.

Schneider, W. J., Cavell, T. A., \& Hughes, J. N. (2003). A sense of containment: Potential moderator of the relation between parenting practices and children's externalizing behaviors. Development and Psychopathology, $15,95-117$.

Steinberg, L., Lamborn, S., Darling, N., Mounts, N., \& Dornbusch, S. (1994). Over-time changes in adjustment and competence among adolescents from authoritative, authoritarian, indulgent, and neglectful families. Child Development, 65, 754-770.

Steinberg, L., Lamborn, S. D., Dornbusch, S. M., \& Darling, N. (1992). Impact of parenting practices on adolescent achievement: Authoritative parenting, school involvement, and encouragement to succeed. Child Development, 63, 1266-1281.

Steinberg, L., Mounts, N., Lamborn, S., \& Dornbusch, S. (1991). Authoritative parenting and adolescent adjustment across various ecological niches. Journal of Research on Adolescence, 1, 19-36.

Strassberg, Z., Dodge, K. A., Pettit, G. S., \& Bates, J. (1994). Spanking in the home and children's subsequent aggression toward kindergarten peers. Development and Psychopathology, 6,445-461.

Vaughn, B. E., Block, J. H., \& Block, J. (1988). Parental agreement on childrearing during early childhood and the psychological characteristics of adolescents. Child Development, 59,1020-1033.

Wauchope, B., \& Straus, M. A. (1990). Physical punishment and physical abuse of American children:

Incidence rates by age, gender, and occupational class. In M. A. Straus \& R. J. Gelles (Eds.), Physical violence 
in American families (pp. 133-148). New Brunswick, NJ: Transaction.

Whisman, M. A., \& McClelland, G. H. (2005). Designing, testing, and interpreting interactions and moderator effects in family research. Journal of Family Psychology, 19, 111-120. 